\title{
A critical review of practices of inclusion and exclusion in the psychology curriculum in higher education
}

\section{Abstract}

Much of South African psychology has pursued the national imperative of critical engagement and reconstruction since 1994, in spite of collusion with Apartheid ideologies before 1994. Critical psychologists who mobilised against apartheid were also active post-1994 in reshaping the discipline and profession. Many of these efforts were directed towards curriculum development to attempt to challenge the dominance of western and northern scholarship in psychology by developing multiple texts that represented local experiences and challenged traditional asocial and ahistorical thinking in psychology. This paper presents critical thoughts on contemporary psychology in higher education, with a particular focus on progress made in curriculum transformation and demographic representativity, to interrogate the extent to which the profession continues to reproduce existing patterns of privilege and inclusion/exclusion. We suggest that considering curriculum as discourse which acts to reproduce larger power relations in society, may be a useful approach to think about inclusion and transformation of the curriculum in psychology.

\section{Introduction}

The Education White Paper 3: A Programme for the Transformation of Higher Education (Department of Education, 1997: 8) included the recognition that there was "an inequitable distribution of access and opportunity for students and staff along lines of race, gender, class and geography". Even though many positive structural changes, such as working towards improving the race and gender demography, institutional transformation forums and the National Student Financial Aid Scheme (NSFAS),

\section{Ronelle Carolissen*}

Department of Educational

Psychology,

University of Stellenbosch,

Stellenbosch

rlc2@sun.ac.za

\section{Tamara Shefer}

Department of Women's and Gender Studies, University of the Western Cape, Bellville

\section{Estian Smit}

Independent scholar

${ }^{*}$ Corresponding author

\section{Keywords:}

curriculum, inclusion, exclusionary practices, transformation, psychology, psychology students, South Africa 
have been implemented, apartheid legacies remain entrenched in contemporary higher education. The Ministerial Committee on Transformation and Social Cohesion in Higher Education (Department of Education, 2008) and the Report on the Stakeholder Summit on Higher Education Transformation (Department of Higher Education and Training, 2010) have documented continuing challenges, originally identified in the White Paper 3 of 1997, that remain in relation to race, gender and class. Political protest by students during 2015 initially called for decolonising the academy through various student movements that collectively united under the banner of a national \#Feesmustfall movement. The focus on inequalities in curriculum shifted to social inequalities of class, foregrounding the impact of poverty intersecting with other inequalities. These student movements have poignantly and overtly drawn attention to continued practices of exclusion in higher education.

Calls for demographic transformation in terms of race and gender have been echoed in psychology. There have been shifts in undergraduate enrolments, at senior levels and in the profession, yet the discipline at all levels remains skewed towards an over-representation of certain groups. Whereas white individuals comprise a small minority of the South African population, they still constitute more than half of South African psychologists, psychology interns and postgraduate students, while black individuals, who represent the majority of the population, still constitute a relatively small minority of South African psychologists, and less than half of psychology interns and postgraduate students (HPCSA, 2013; Stats SA, 2013). Furthermore, Psychology is increasingly feminised from undergraduate levels to professional practice. In 2013, the Health Professions Council of South Africa (HPCSA) figures showed that $79.7 \%$ of interns and $77.4 \%$ of postgraduate students were women.

Much debate about social inclusion has raged over the last 30 years as to how psychology may be transformed to be an inclusive discipline. In addition to demographic transformation in the discipline, the psychology curriculum has been identified as a key area of challenge in addressing continued disparities in the training of psychologists and in addressing the mental health care needs of South Africa. It is therefore crucially important to consider the psychology curriculum in debates on social cohesion, and especially the role that psychology can play towards more active and inclusive citizenship by developing socially critical citizens in and through educational spaces in higher education. Even though debates about a more relevant psychology started in the 1980s, and while various authors have subsequently suggested that the curriculum needs to be changed, this has remained notoriously difficult to achieve in a comprehensive and successful manner. The present paper therefore aims to contribute to the goal of transforming the discipline and practice of psychology by critically reviewing the literature about exclusion and inclusion in psychology, specifically with respect to

PINS [Psychology in Society] 49 • $2015 \mid 8$ 
the curriculum taught in South African higher education over the last two decades of post-apartheid democratic reform. This engagement includes studies that document the perceptions and experiences of students. In reviewing this literature critically, we argue for the continued need for critical work on the curriculum that go beyond current approaches towards a more radical transformation in the discipline and profession.

\section{Curriculum, discourse and social cohesion}

Curriculum refers to what is taught (content), how teaching takes place (process) and the ethical and moral practices of teachers' work (context) with students (Pinar, 2012). It is thus a symbolic process whereby reality is reproduced, repaired and transformed in historical and social context and through which we (both students and educators) may articulate our experience in the world by studying bodies of knowledge. This well-established understanding of curriculum has numerous implications for social cohesion and curriculum as discourse. In this understanding of curriculum, notions of social cohesion and how to work towards it, are important. Social cohesion is generally thought of as processes and practices that contribute to a common sense of values, purpose and belonging in nations and organisations. It is nevertheless a contested concept, as a drive towards cohesion can re-inscribe dominance, promote assimilation and obliterate contestation and difference (Harris, 2013). Established notions of cohesion assume consensus, whereas contestation and engagement that may lead to shared understanding in common contact zones (Ahmed, 2004), are part of creating opportunities for criticality (Young, 1990).

An extension to the argument of social cohesion as contestation, and of particular importance to thinking about curriculum, is Laclau and Mouffe's (1985) theory of discourse that draws on politics and occurrence of social conflict. They highlight, not language and meaning, but the construction of antagonisms as sources of social conflict. They argue that antagonisms occur because actors or social agents are unable to attain their identities and conflict occurs in the blockage or failure of identities. The failure of identity is a mutual experience for both antagonising and antagonised. Discourse analyses using this framework would describe the ways in which identities of agents are blocked as well as the resources used to block identities. If this thinking is applied to disciplines and curricula, they may be viewed as discourses, each with a characteristic structure and an articulatory practice (Howarth, 2000). Out of these structures and practices, professionals or professional identities are meant to emerge. By including some and excluding others along discriminatory lines, social antagonisms may arise since some social agents may experience a "blockage of identity" (Howarth, 2000: 105). In this sense, disciplines and curricula can be seen as blocking devices for some potential professionals and studying curriculation as a facilitator and a barrier may indicate ways in which social cohesion through equity can be advanced. 
Honneth (1999) argues similarly in relation to the violation of identity claims as blocking the emergence of social recognition through socially regulated occupations. Thus, our engagement with the curriculum and professions goes beyond the concerns of equity as representivity or equal opportunities. It also shifts the interest in equity into the realm of social recognition and cohesion. In fact, interrogation of dominant norms and practices, as well as antagonisms, are desirable in an attempt to renegotiate conditions and practices of inclusion to constitute an order in which difference is recognised and constituted as central to social cohesion. These critiques of social cohesion as well as understandings of curriculum suggest that educational spaces such as classrooms may constitute contact zones in which deep engagements with difference, often characterised by contestation, are possible (Bozalek et al, 2010) and which are not driven by normative understandings of social cohesion. The essence inherent in recognition of difference may contribute to a social cohesion not based on consensus but paradoxically on contestation. In South African psychology, the core debates about transformation of the discipline over the last 30 years are reflected in the nexus of curriculum, social cohesion and discourse.

\section{Contemporary context of psychology as a professional discipline in higher education: Concerns about a lack of progress}

South African psychology, together with its skewed demographic representativity, continues to be a cause of concern despite significant efforts at transforming the discipline and profession during the country's first two decades of democracy. Emerging from a history of collusion with apartheid ideologies, much of South African psychology has followed the national imperative of critical engagement and reconstruction since the demise of apartheid in 1994. Critical psychologists who mobilised against apartheid were also active post-1994 in reshaping the discipline and profession, reflected consistently in the emergence and subsequent issues of this journal, Psychology in society (see for example, founding edition of PINS, 1983). Contemporary efforts at transformation have been directed at evaluating the relevance of psychology as discipline and profession in South Africa for the majority of South Africans (for example, Stevens, 2003; Suffla \& Seedat, 2004; Pillay, 2009; Cooper \& Nicholas, 2012). In this respect, studies have foregrounded structural inequalities, lack of demographic representativeness and the role of psychology in transformation and "undoing" apartheid legacies (for example, Ahmed \& Pillay, 2004; De la Rey \& Ipser, 2004; Pretorius, 2008; Sher \& Long, 2012). There has also been increased grappling with issues of cultural, religious and epistemological relevance - particularly efforts at Africanising psychology - gaining momentum in South Africa (for example, Holdstock, 2000; Yen \& Wilbraham, 2003a, 2003b; Mkhize, 2004a, 2004b; Eskell-Blokland, 2005; Patel \& Shikongo, 2006; Diale \& Fritz, 2007; Baloyi, 2008; Ngcobo \& Edwards, 2008; Eskell-Blokland, 2009; Ruane, 2010; Bojuwoye \& Edwards, 2011; Eagle \& Long, 2011; Edwards, 2011; Makunga, Thwala \& Edwards, 2011; Sodi \& Bojuwoye, 2011; Ebersöhn, 2012; Matoane, 2012; Theron, Theron \& Malindi, 2013; Laher, 
2014; Padayachee \& Laher, 2014) and other African countries (for example, Mpofu, 2002; Bandawe, 2005; Nwoye, 2011; Javangwe, 2013).

Recommendations around transforming the curriculum have included the following: taking African cultures, languages, healing processes and experiences as the point of departure for the psychology curriculum (Baloyi 2008); establishing departments where postgraduate students research African worldviews in order to create a foundation for an African indigenous psychology (Juma 2011); and introducing dedicated courses in African psychology (Nwoye, 2011; Matoane, 2012; Javangwe, 2013) and dedicated modules on cultural issues (Eagle, 2005; Matoane, 2012). Critical psychologists and others have also cautioned against reproducing essentialised and ahistorical notions of culture and ethnicity in this pursuit (Rashed, 2013) and perpetuating misperceptions that equate culture with black and poor people, but not white and middleclass people (Yen \& Wilbraham, 2003b).

Some efforts at transformation and inclusive practices in psychology, specifically in higher education contexts, were directed towards generating new materials for the curriculum to challenge the dominance of western and northern scholarship in psychology. The approach has been to produce texts that represent local contexts and experiences and challenge traditional asocial and ahistorical thinking in psychology. Thus many of the well-known critical psychologists in South Africa invested much time and energy from the mid-1990s onwards in developing alternative, critical and more locally representative texts to draw on in the curriculum (for example, De la Rey, Duncan, Shefer \& Van Niekerk, 1997; Duncan et al, 2002; Hook et al, 2004; Ratele et al, 2004; Shefer, Boonzaier \& Kiguwa, 2006; Duncan et al, 2007; Mpofu, 2011). These textbook editions were intended to not only provide more contextual content that students could identify with but also to challenge the over-reliance in South African psychology on North American textbooks and scholarship. While these texts have been significant and authorship has shifted in terms of race and gender, psychology training and the profession continue to represent a skewed demographic in terms of class, racial and gender categories, which speaks to continued challenges in the curriculum. Thus while it has been an important project to develop more local, critical texts in psychology, much remains to be done. Clearly more work interrogating the curriculum in a more comprehensive way, and in particular students' experience of their training, is required. This calls for a better understanding of who our students are and what their experiences are in the discipline.

\section{Psychology students in South African higher education: Perceptions and experiences}

Psychology is a popular undergraduate subject among historically disadvantaged students, both locally and internationally. In South Africa, psychology was among the top three fields of undergraduate enrolments in the Humanities from 2004 to 2008 (ASSAf, 
2011: 65) and black women constituted the largest group of undergraduate enrolments in psychology by 2002 (cf Skinner \& Louw, 2009: 85). Other South African studies similarly highlight how local universities attract large numbers of undergraduate black students to psychology (Sedumedi, 2002; Pillay, Bundhoo \& Ngcobo, 2008), which is also a trend for black and minority ethnic (BME) students internationally (see for example, Turpin \& Fensom, 2004).

A high number of enrolments in psychology at undergraduate level can partly be ascribed to the fact that psychology is a requirement in many health, humanities and natural science degree programmes like social work, dietetics and sports science (Sedumedi, 2002; Pillay, Bundhoo \& Ngcobo, 2008; ASSAf, 2011). Undergraduate numbers of black students mask the continued racialised profile where those who continue to professional levels in psychology remain skewed towards white and historically advantaged communities. Compared to white students, the numbers of black students frequently dwindle significantly in postgraduate psychology training, and black psychologists continue to be under-represented among professional psychologists both nationally and globally. In the United Kingdom, for example, a report in 2004 found that "there appears to be a loss of BME candidates following graduation, for both psychology assistant and trainee posts" and that the representation of psychologists from such backgrounds decreases at different levels of the workforce (Turpin \& Coleman, 2010: 18).

Similar challenges are experienced in South Africa with regard to achieving substantial increases in the numbers of black postgraduate students and psychologists. The Health Professions Council of South Africa (HPCSA, 2013) register shows that in 2013 white individuals still comprised (as far as could be determined) $58.4 \%$ of psychologists in South Africa, $53.2 \%$ of psychology interns and $52.7 \%$ of postgraduate students, despite their population group only comprising $8.7 \%$ of the South African population (Stats SA, 2013). In contrast, black individuals (here understood as African, Coloured and Indian/Asian individuals), whose population groups comprised $91.3 \%$ of the South African population in 2013 (Stats SA, 2013), constituted (as far as could be determined) only $20 \%$ of South African psychologists, $45.3 \%$ of psychology interns and $44.8 \%$ of postgraduate students (HPCSA, 2013, our own calculation of percentages). Given the large percentage (21.5\%) of unspecified/other psychologists (psychologists who did not specify "race" during professional registration), it is however not possible to determine exact figures for the various population groups.

Notwithstanding postgraduate black students' comparatively low numbers, some progress has been made towards attaining the Professional Board for Psychology's "resolution that graduate professional psychology programmes should have an intake ratio of 50/50 (i.e. black/white students) by 1 January 2004" (Pillay \& Siyothula, 2008: 
733), albeit a decade after the initial deadline. Additionally, at least in the public sector, which saw a near doubling of the numbers of psychologists in 2013 (resulting in public sector psychologists comprising $14.8 \%$ of all South African psychologists), African psychologists (57.1\%) for the first time outnumbered white psychologists (30.2\%), with black psychologists as a whole reaching nearly $70 \%$ in the public sector (Health Systems Trust, 2014, our own calculation of percentages).

Between 2007 and 2013 there were also increases in the numbers and relative percentages of South African psychologists as a whole and across all population groups, with the exception of other/unspecified psychologists, whose numbers showed a significant decline. The numbers of African and coloured psychologists more than doubled in this seven-year period, the number of Indian/Asian psychologists increased by more than a third, and the number of white psychologists by more than a quarter (Health Systems Trust, 2014). ${ }^{1}$ However, despite the gradual increases in the numbers and relative percentages of under-represented psychologists, it is ironic to note that white psychologists still showed by far the biggest increase during the period. ${ }^{2}$

Notwithstanding this continued context of skewed demographics, there has been little research directed at understanding the underlying discourses, inside and outside universities, that shape these disparities. Only a few studies deal to some extent with psychology students' views on and experiences of the curriculum, and even then it is seldom the exclusive focus of the study as a whole (for example, Sedumedi 2002; Patel \& Shikongo, 2006; Nair, 2008; Pillay, Bundhoo \& Ngcobo, 2008; Chitindingu, 2012; Cornell, 2012; Mhambi, 2012). Four issues emerge in students' perceptions and reported experiences of the discipline.

The first issue relates to the transferability of training to diverse contexts and students' own communities. While one quantitative study showed high levels of agreement that psychology may be relevant and of benefit to their social context and communities (Pillay, Bundhoo \& Ngcobo, 2008: 358), most studies found that many students feel that psychology in its current form is not addressing the needs and contexts of the majority of the population, nor preparing them for working with diverse communities or engaging with issues of 'race' and racism in their interactions with others (Patel \& Shikongo, 2006; Nair, 2008; Ruane, 2010; Chitindingu 2012; Cornell 2012).

\footnotetext{
The number of registered psychologists changed as follows between 2007 and 2013: African psychologists increased from 390 to 803 , coloured psychologists from 125 to 277 , Indian/Asian psychologists from 279 to 452 and white psychologists from 3224 to 4 448. Other/unspecified psychologists decreased from 2292 to 1642 . The total number of psychologists increased from 6310 to 7622 (Health Systems Trust, 2014).

2 The relative percentages of registered psychologists changed as follows between 2007 and 2013: African psychologists increased from $6.2 \%$ to $10.5 \%$, coloured psychologists from nearly $2 \%$ to $3.6 \%$, Indian/Asian psychologists from $4.4 \%$ to $5.9 \%$ and white psychologists from $51.1 \%$ to $58.4 \%$. Other/unspecified psychologists decreased from $36.3 \%$ to $21.5 \%$ (cf. Health Systems Trust, 2014, our own calculation of percentages).
} 
Student concerns included a need for more Black psychologists/psychologists of colour and psychologists in disadvantaged communities (Nair, 2008; Ruane, 2010; Cornell, 2012); the dominance of English or Afrikaans and lack of indigenous language emphasis that do not equip psychologists to work with the majority of language groups in South Africa (Ruane, 2010; Chitindingu, 2012; Cornell, 2012; Mhambi, 2012); and a lack of representation of their own communities and lived realities in the curriculum (Nair, 2008; Chitindingu, 2012). Further concerns reflected an inattention to spirituality and an overly secular bias that reportedly results in discomfort and compromise of religious integrity by religious students (Patel \& Shikongo, 2006); the teaching of inappropriately individualist approaches, and the westernised focus of much of the course content (Chitidingu, 2012; Cornell, 2012). Students also highlighted a related ambivalence about the effectiveness of psychological methods for most South Africans (Cornell, 2012) and suggested that the curriculum is too theoretical and lacks a focus on practical and relevant experience in working with people (Nair 2008; Cornell, 2012). Ruane's (2010) study foregrounds in particular the perception of the racialisation of the profession: participants constructed psychologists "as 'old white men', who were 'racist, unsympathetic, uncaring and unavailable to communities", "elitist and 'too far removed from the community to be of assistance to black people", preoccupied with "showing what they could do", neglecting to "take the time to develop a relationship with the client" and not knowing or understanding their clients' culture (Ruane, 2010: 219-220).

A second issue relates to socio-economic concerns and perceptions of income in psychology. For many Black psychology students, affording study costs and easing familial income burdens are primary concerns, so careers with shorter training periods such as social work or even law, may be viewed as more viable options than psychology (cf. Sedumedi 2002; Mudhovozi, 2011; Cornell, 2012). On the other hand, the difficulty of affording student fees did not feature as a prominent concern for white students, but they were concerned about whether they would be able to earn a good income as a psychologist (Cornell, 2012). Moreover, there was a perception among students that psychology careers that are engaged with social issues are particularly unviable in material terms (Cornell, 2012). Another deterrent highlighted by students is "the high cost of consulting a clinical or counselling psychologist”, making psychologists' services inaccessible (Cornell, 2012: 21).

The third issue relates to entry requirements and the inverted pyramid structure of South African psychology career development. Historically, in South African universities, psychology is a subject located in a Bachelor's Degree and students may major in it. It is only at the fourth-year, Honours level that students begin to specialise in psychology. At this level, the large classes of undergraduate psychology are reduced to far smaller classes. At the next level of selection for admission to 
professional master's degrees, a further thinning out takes place, with only a small group of between 6 to 12 students remaining. ${ }^{3}$ This is a highly competitive process, especially in the case of clinical psychology (Traub \& Swartz, 2013), and is experienced as daunting by students (Mhambi, 2012). Cornell (2012) found that departmental warnings of the competitiveness of entry into postgraduate training unintentionally deterred many Black students from applying.

Finally, some studies show that psychology students find the course material and training challenging, both intellectually and emotionally, which may relate to unsupportive teaching and learning practices in psychology (Sedumedi 2002; Mhambi, 2012), but also to the lack of relevance to students' lived realities pointed out above. Thus students report that psychology posed a greater academic challenge than they had anticipated when enrolling (Cornell, 2012; Mhambi, 2012) and statistics in particular, still viewed as foundational to psychological "science", is generally found to be a challenge for many students (Coetzee \& Van der Merwe, 2010; Cornell, 2012). The requirement that students absorb large volumes of Eurocentric theory and unfamiliar epistemologies about human behaviour also poses difficulties in understanding and application of knowledge (Nair, 2008; Mhambi, 2012). This contributes to feelings of inadequacy in relation to white students who seem to experience curricular inclusion and therefore engage more easily with the "theoretical jargon" (Nair, 2008: 90). As a result, the curriculum brings about social antagonisms between students. Nair (2008) mentions how "[t]he theoretical content of the master's course, in particular, was experienced as a site of exclusion" (90) by students of colour, making case formulations difficult, and how "trainees felt hamstrung by for example their inability to operationalise psychodynamic theories taught" (168). When a curriculum clearly functions in a way that primarily includes students who are already in positions of privilege, while further marginalising and blocking the identities of students who are not, then we need fundamental and far-reaching change to transform it from an instrument of oppression to a tool that can help to bring about equitable social relations between citizens.

\section{Conclusion and recommendations}

In spite of forty years of concerns about minimal demographic, curricular and other forms of inclusion in psychology for the majority of South Africans and considered efforts to redress this, current research suggests that some progress in inclusion is evident but that significant areas of exclusion still exist. A range of factors, both material and discursive, may be reproducing exclusionary practices in South African psychology. These include an experience of a lack of contextual relevance and resonance of the

\footnotetext{
While an attempt has been made to adjust this pyramid structure by creating a professional degree through the Bachelor of Psychology programme, resulting in registration as psychological counselor, this has not been entirely successful across higher education in South Africa and the practice-orientated categories of clinical, counseling and educational psychologists remain highly exclusive.
} 
curriculum to the social context of many students, socio-economic concerns and financial challenges, insecurity about selection in highly competitive postgraduate programmes, and the notion that the curriculum is difficult. All of these factors reinscribe, both implicitly and explicitly, the skewed demographics of the profession as well as its perceived elitism and collusion with power. What is evident from studies of student experiences of the psychology curriculum in South African higher education is that they are deeply concerned with the relevance of the discipline of psychology. Participants in most of these studies drew mostly on a cultural, racialised and, to some extent, gendered discourse to explain the inappropriateness of the curriculum, since this is the discourse that is socially available to contemporary South Africans.

Few authors in psychology consider the importance of curriculum as discourse which acts to reproduce larger power relations in a society (Howarth, 2000). Thus transforming psychology is more complex than simply adding a component on culture or inserting more Black students into a classroom. Rather, we argue the importance of understanding disciplines and curriculum as discourse which serves particular functions, including policing and regulating the boundaries of entry into the profession. Disciplines, we suggest, following Howarth (2000), may operate in similar ways that oppressive systems such as patriarchy and white supremacy do. This perspective may provide different insights into affordances and constraints regarding transformation of curriculum. When we view curriculum as discourse, disciplines and curriculum are illuminated as entities, each with a characteristic structure and an articulatory practice that regulate occupations and social recognition (Honneth, 1999; Howarth, 2000). Since disciplines and curricula can act to block the identities of some individuals and groups and prevent them from entering certain professions, it is important to explore ways in which curriculation can advance social cohesion through equity.

Even though it is important to monitor representativity in the discipline, it is also crucial to think beyond concerns of equity as representativity or equal opportunities, or as simply adding "cultural" issues to the curriculum. Rather, we need to expand our emphasis on equity, inclusivity and adaptability into the curriculum through closer attention to the discursive functions of curriculum in the teaching of psychologists. It is important to acknowledge that many students, as suggested in the studies reviewed, continue to feel "out of place" in psychology. If one views the psychology curriculum as discourse, the expectation of "perfect comfort" and/or belonging may be misplaced. In this view, marginalised social positioning will always attract a sense of discomfort within disciplines. So rather than aspiring to be completely "comfortable", it is important to consider how we could negotiate in constructive ways a "comfortable discomfort" for ourselves and all our students. This does not mean maintaining a 
status quo in which some students with more privilege feel more comfortable, but rather facilitating their reflexivity in this respect, and therefore their discomfort, so that all students are engaged in a discomforting process of learning, arguably key to a critical reflexive praxis (Boler \& Zembylas, 2003; Zembylas, 2013).

Thus the argument about facilitating diversity in curriculum should not devolve to the inclusion of "multicultural" components or culture mainstreaming, especially when this is generally interpreted using essentialised notions of culture or identity that reinscribe binaristic difference and inadvertently rationalise inequality. Challenging the lack of cultural relevance and appropriateness of mainstream psychology should therefore proceed from a recognition that all persons are shaped by their socio-cultural backgrounds, and be informed by historically and contextually sensitive understandings of the complex interplay of a great diversity of socio-cultural influences and expressions throughout society, rather than becoming overly fixated on certain dominant cultural, religious, "race" or ethnic group labels. Such approaches may risk cultural reification and would create caricatures instead of being responsive to the complexities and intersectionalities of people's lived realities.

More important than adding and stirring "culture" and "diverse identity", is the development of critical reflexive scholarship and teaching and learning in psychology. Critical and social justice pedagogies, with emphases on learner-centred, agentic and reflexive practices of teaching and learning, are arguably key in such a project (Boler \& Zembylas, 2003; Carolissen et al, 2010). Such a critical reflexivity implicates students and lecturers, a project that may also assist in developing the capacity to engage constructively with discomfort rather than being disabled by it.

\section{Acknowledgement}

The financial assistance of the National Research Foundation: Education Research in South Africa, towards this research is hereby acknowledged. Opinions expressed and conclusions arrived at are those of the authors and are not attributed to the National Research Foundation.

\section{References}

Academy of Science of South Africa (ASSAf) (2011) Consensus study on the state of the humanities in South Africa: Status, prospects and strategies. Pretoria: ASSAf. http://www.assaf.co.za/wp-content/uploads/2011/09/2011-Humanity-final-proof-11August-2011.pdf. 
Ahmed, R \& Pillay, A L (2004) Reviewing clinical psychology training in the post-apartheid period: Have we made any progress? South African Journal of Psychology, 34(4), 630-656.

Ahmed, S (2004) The cultural politics of emotion. New York: Routledge.

Baloyi, L (2008) Psychology and psychotherapy redefined from the viewpoint of the African experience. Doctoral dissertation in Psychology, University of South Africa. http://umkn-dsp01.unisa.ac.za/handle/10500/1346.

Bandawe, C R (2005) Psychology brewed in an African pot: Indigenous philosophies and the quest for relevance. Higher Education Policy, 18(3), 289-300.

Bojuwoye, O \& Edwards, S (2011) Integrating ancestral consciousness into conventional counselling. Journal of Psychology in Africa, 21(3), 375-381.

Boler, M \& Zembylas, M (2003) Discomforting truths: The emotional terrain of understanding difference, in Trifonas, P P (ed) (2003) Pedagogies of difference:

Rethinking education for social change. New York: Routledge.

Bozalek, V., Carolissen, R., Leibowitz, B., Nicholls, L., Rohleder, P. \& Swartz, L. (2010). Engaging with difference in higher education through collaborative inter-institutional pedagogical practices. South African Journal of Higher Education, 24(6), 1023-1037.

Carolissen, R, Rohleder, P, Bozalek, V, Swartz, L \& Leibowitz, B (2010) “Community psychology is for poor, black people": Pedagogy and teaching of community psychology in South Africa. Equity \& Excellence in Education, 43(4), 495-510.

Chitindingu, E (2012) Students' views on the inclusion of multicultural perspectives into the psychology curriculum at two South African universities: An Afrocentric analysis. Master's thesis, School of Psychology, University of KwaZulu-Natal. http://researchspace.ukzn.ac.za/xmlui/handle/10413/8081.

Coetzee, S \& Van der Merwe, P (2010) Industrial psychology students' attitudes towards statistics. SA Journal of Industrial Psychology, 36(1), Art. 843, 8 pages.

Cooper, S \& Nicholas, L (2012) An overview of South African psychology. International Journal of Psychology, 47(2), 89-101. 
Cornell, J (2012) UCT undergraduate psychology students' perceptions of psychology in the context of the 'relevance debate'. Honours project, Department of Psychology, University of Cape Town, Cape Town. http://www.psychology.uct.ac.za/sites/default/ files/image tool/images/117/Josephine.Cornell.pdf.

De la Rey, C, Duncan, N, Shefer, T \& Van Niekerk, A (eds) (1997) Contemporary issues in human development: A South African focus. Johannesburg. International Thomson.

De la Rey, C \& Ipser, J (2004) The call for relevance: South African psychology ten years into democracy. South African journal of psychology, 34(4), 544-552.

Department of Education (1997) Education White Paper 3: A Programme for the Transformation of Higher Education. Government Gazette, 386(18207), 15 August 1997.

Department of Education (2008) Report of the Ministerial Committee on Transformation and Social Cohesion and the Elimination of Discrimination in Public Higher Education Institutions. Pretoria: Government Printers.

Department of Higher Education and Training (2010) Report on the Stakeholder Summit on Higher Education Transformation. Report of a summit held on 22-23 April 2010 at Cape Peninsula University of Technology, Cape Town. https://www.cput. ac.za/storage/services/transformation/he_transformation_summit_report.pdf.

Diale, B \& Fritz, E (2007) Indigenous knowledge and learning development, in Duncan, N, Bowman, B, Naidoo, A, Pillay, J \& Roos, V (eds) (2007) Community Psychology: Analysis, context and action. Cape Town: UCT Press.

Duncan, N, Bowman, B, Naidoo, A, Pillay, J \& Roos, V (eds) (2007) Community Psychology: Analysis, context and action. Cape Town: UCT Press.

Duncan, N, Gqola, P, Hofmeyr, M, Shefer, T, Malunga, F \& Mashige, M (eds) (2002) Discourses on difference: Discourses on oppression. Cape Town: CASAS.

Eagle, G (2005) "Cultured clinicians": The rhetoric of culture in clinical psychology training. PINS (Psychology in society), 32, 41-64.

Eagle, G \& Long, C (2011) In our culture, in our gender: Implications of the culture/ gender interface for South African psychotherapists. Feminism \& Psychology, 21(3), 336-353. 
Ebersöhn, L (2012) Imagining career resilience research and training from an indigenous knowledge production perspective. South African Journal of Higher Education, 26(4), 800-812.

Edwards, S D (2011) A psychology of indigenous healing in Southern Africa. Journal of Psychology in Africa, 21(3), 335-347.

Eskell-Blokland, L M (2005) Voice to the silent: An ecology of local knowledge in psychology. Doctoral thesis, Department of Psychology, University of Pretoria, Pretoria. http://www.repository.up.ac.za/handle/2263/27932.

Eskell-Blokland, L M (2009) Listening to oral traditions in a re-searching for praxis in a non-western context. Journal of Health Management, 11(2), 355-373.

Harris, A (2013) Young people and everyday multiculturalism. New York: Routledge.

Health Professions Council of South Africa (HPCSA) (2013) HPCSA statistics - 11 June 2013. http://www.healthlink.org.za/indicators/HumanResources/HPCSA/. Date retrieved: 31 July 2014.

Health Systems Trust (HST) (2014) Health and related indicators.

http://www.healthlink.org.za/healthstats/. Date retrieved: 12 July 2014.

Holdstock, T L (2000) Re-examining psychology: Critical perspectives and African insights. London: Routledge.

Honneth, A (1999) The social dynamics of disrespect: On the location of critical theory today, in Dews, P (ed) (1999) Habermas: A Critical Reader. Oxford: Blackwell.

Hook, D, Mkhize, N, Kiguwa, P \& Collins, A (eds) (2004) Critical psychology. Lansdowne: UCT Press.

Howarth, D (2000) Discourse. Buckingham, MK: Open University Press.

Javangwe, G (2013) How to Africanize psychology in Zimbabwean universities:

An introductory note. Journal of Black Psychology, 39(3), 336-341.

Juma, J O (2011) African worldviews: Their impact on psychopathology and psychological couselling. Master's thesis in Psychology, University of South Africa, Prertoria. http://umkn-dsp01.unisa.ac.za/handle/10500/5760. 
Laclau, E \& Mouffe, C (1985) Hegemony and socialist strategy. London: Verso.

Laher, S (2014) An overview of illness conceptualizations in African, Hindu, and Islamic traditions: Towards cultural competence. South African Journal of Psychology, 44(2), 191-204.

Makunga, N, Thwala, J \& Edwards, S (2011) The meanings of an animal wristband (isiphandla) in KwaZulu-Natal, South Africa. Journal of Psychology in Africa, 21(3), 371-373.

Matoane, M (2012) Locating context in counselling: The development of indigenous psychology in South Africa. Psychotherapy and Politics International, 10(2), 105-115.

Mhambi, R (2012) An exploration into the subjective emotional experiences the MSc 1-clinical psychology trainees at the University of Limpopo (Medunsa Campus) during their first block of training. Master's thesis in Clinical Psychology, Faculty of Health Sciences, University of Limpopo. http://ul.netd.ac.za/handle/10386/1077.

Mkhize, N (2004a) Psychology: An African perspective, in Hook, D, Mkhize, N, Kiguwa, P \& Collins, A (eds) (2004) Critical psychology. Lansdowne: UCT Press.

Mkhize, N (2004b) Socio-cultural approaches to psychology: Dialogism and African conceptions of the self, in Hook, D, Mkhize, N, Kiguwa, P \& Collins, A (eds) (2004)

Critical psychology. Lansdowne: UCT Press.

Mpofu, E (2002) Psychology in sub-Saharan Africa: Challenges, prospects and promises. International Journal of Psychology, 37(3), 179-186.

Mpofu, E (ed) (2011) Counseling people of African ancestry. Cambridge: Cambridge University Press.

Mudhovozi, P (2011) College adaption experiences of married female undergraduate students: An exploratory study. Journal of Psychology in Africa, 21(3), 465-468.

Nair, S (2008) Psychologists and race: Exploring the identities of South African trainee clinical psychologists with reference to working in multiracial contexts.

DPhil dissertation, Department of Psychology, University of Stellenbosch. http://scholar.sun.ac.za/handle/10019.1/1489. 
Ngcobo, H S B \& Edwards, S D (2008) Self-perceived multicultural counselling competencies in South African psychologists: A basis for practice guidelines. Journal of Psychology in Africa, 18(4), 647-652.

Nwoye, A (2011) An outline and rationale for the inclusion of African psychotherapy as an undergraduate course in an African university. Paper prepared for the Fourth Multiversity Conference on "Decolonizing our Universities”, held in Tanjung Bungah, Penang, Malaysia, 2729 June 2011. http://multiworldindia.org/wp-content/ uploads/2009/12/Augustine-Nwoye2.pdf.

Padayachee, P, \& Laher, S (2014) South African Hindu psychologists' perceptions of mental illness. Journal of Religion and Health, 53(2), 424-437.

Patel, C J \& Shikongo, A E (2006) Handling spirituality/religion in professional training: Experiences of a sample of Muslim psychology students. Journal of Religion and Health, 45(1), 93-112.

Pillay, A L (2009) Apartheid and post-apartheid intern clinical psychology training in South Africa. Psychological Reports, 105(3), 697-700.

Pillay, A L, Bundhoo, H Y \& Ngcobo, H S B (2008) Mauritian and South African students' views on studying psychology. Journal of Psychology in Africa, 18(2), 355-360.

Pillay, A L \& Siyothula, E B (2008) The training institutions of black African clinical psychologists registered with the HPCSA in 2006. South African Journal of Psychology, 38(4), 725-735.

Pinar, W F (2012) What is curriculum theory? New York: Routledge.

Pretorius, G (2008) Race, sex and class in psychology: Vision of hope for a fair and just South Africa. Journal of Psychology in Africa, 18(2), 349-354.

Psychology in Society (1983) Psychology in society (PINS) 1.

Rashed, M A (2013) Talking past each other: Conceptual confusion in "culture" and “psychopathology". South African Journal of Psychiatry, 19(1), 12-14.

Ratele, K, Duncan, N, Hook, D, Mkhize, N, Kiguwa, P \& Collins, A (eds) (2004) Self, community and psychology. Cape Town: University of Cape Town Press. 
Ruane, I (2010) Obstacles to the utilisation of psychological resources in a South African township community. South African Journal of Psychology, 40(2), 214-225.

Sedumedi, S D (2002) Students' perceptions and expectations of a first-year psychology course at the University of the North. South African Journal of Higher Education, 16(3), 167-176.

Shefer, T, Boonzaier, F \& Kiguwa, P (eds) (2006) The gender of psychology. Cape Town: UCT Press.

Sher, D \& Long, W (2012) Historicising the relevance debate: South African and American psychology in context. South African Journal of Psychology, 42(4), 564-575.

Skinner, K \& Louw, J (2009) The feminization of psychology: Data from South Africa. International Journal of Psychology, 44(2), 81-92.

Sodi, T \& Bojuwoye, O (2011) Cultural embeddedness of health, illness and healing: Prospects for integrating indigenous and western healing practices. Journal of Psychology in Africa, 21(3), 349-356.

Statistics South Africa (Stats SA) (2013) Mid-year population estimates 2013. Statistical release P0302. Pretoria: Statistics South Africa. http://beta2.statssa.gov.za/ publications/P0302/P03022013.pdf.

Stevens, G (2003) Academic representations of "race" and racism in psychology: Knowledge production, historical context and dialectics in transitional South Africa. International Journal of Intercultural Relations, 27(2), 189-207.

Suffla, S \& Seedat, M (2004) How has psychology fared over ten years of democracy? Achievements, challenges and questions. South African Journal of Psychology, 34(4), 513-519.

Theron, L C, Theron, A M C \& Malindi, M J (2013) Toward an African definition of resilience: A rural South African community's view of resilient Basotho Youth. Journal of Black Psychology, 39(1), 63-87.

Traub, C M \& Swartz, L (2013) White clinical psychology trainees' views on racial equity within programme selection in South Africa. Teaching in Higher Education, 18(8), 846-858. 
Turpin, G \& Coleman, G (2010) Clinical psychology and diversity: Progress and continuing challenges. Psychology Learning \& Teaching, 9(2), 17-27.

Turpin, G \& Fensom, P (2004) Widening access within undergraduate psychology education and its implications for professional psychology: Gender, disability and ethnic diversity. Leicester: The British Psychological Society.

Yen, J \& Wilbraham, L (2003a) Discourses of culture and illness in South African mental health care and indigenous healing, Part I: Western psychiatric power. Transcultural Psychiatry, 40(4), 542-561.

Yen, J \& Wilbraham, L (2003b) Discourses of culture and illness in South African mental health care and indigenous healing, Part II: African mentality. Transcultural Psychiatry, 40(4), 562-584.

Young, I M (1990) Justice and the politics of difference. Princeton: Princeton University Press.

Zembylas, M (2013) Critical pedagogy and emotion: Working through "troubled knowledge" in posttraumatic contexts. Critical Studies in Education, 54 (2), 176-189. 